\title{
Development of the Accessibility Guidelines for Mobility Handicapped Persons in Passenger Ship
}

\author{
† Hongtae Kim, Jong-Gap Lee* \\ †,* Maritime Safety Research Division, Maritime \& Ocean Eng. Research Institute, KIOST, Daejeon 305-343, Republic. of Korea
}

\begin{abstract}
The ratio of the mobility handicapped person is about $25.8 \%$ of the total population in Korea(MCT, 2006). In order to prepare for the enforcement of the "Transportation Services Improvement Act for the Mobility Handicapped People"(MCT, 2006), various equipments and installations should be developed to ensure appropriate safety level for the mobility handicapped persons in maritime transportation. While approximately 10 million people are using domestic passenger vessels annually, preferences for maritime transport is very low, especially for the mobility handicapped. This study reviewed a current status of the mobility handicapped person in domestic passenger ship and analysed the improvement plan for them. To investigate the current status of domestic passenger vessel usage by the mobility handicapped, to analysis the requirements for amenities necessary for the mobility handicapped and select the ones to be developed based on the investigated results and to do feasibility study of barrier-free ship.
\end{abstract}

Key words : accessibility, mobility handicapped persons, passenger ship, maritime safety, barrier-free ship

\section{Introduction}

In this study, the movement characteristics of the mobility handicapped persons were investigated and examined the domestic and foreign guidelines, standards and statute to develop the "Accessibility Guidelines for the Mobility Handicapped Persons in Passenger ship". The mobility handicapped person means a person whose mobility is limited as a result of permanent severe physical disability such as the disabled persons, the pregnant women, and the elderly persons.

To gather present domestic statistics and problems for mobility handicapped persons who want to use passenger ships, questionnaire and field surveys were conducted. Based on the results of investigations, requirements of the mobility facility were analyzed, and those were reflected to the accessibility guidelines.

Fig. 1 shows process for development of "Accessibility Guidelines for the Mobility Handicapped Persons in Passenger ship."

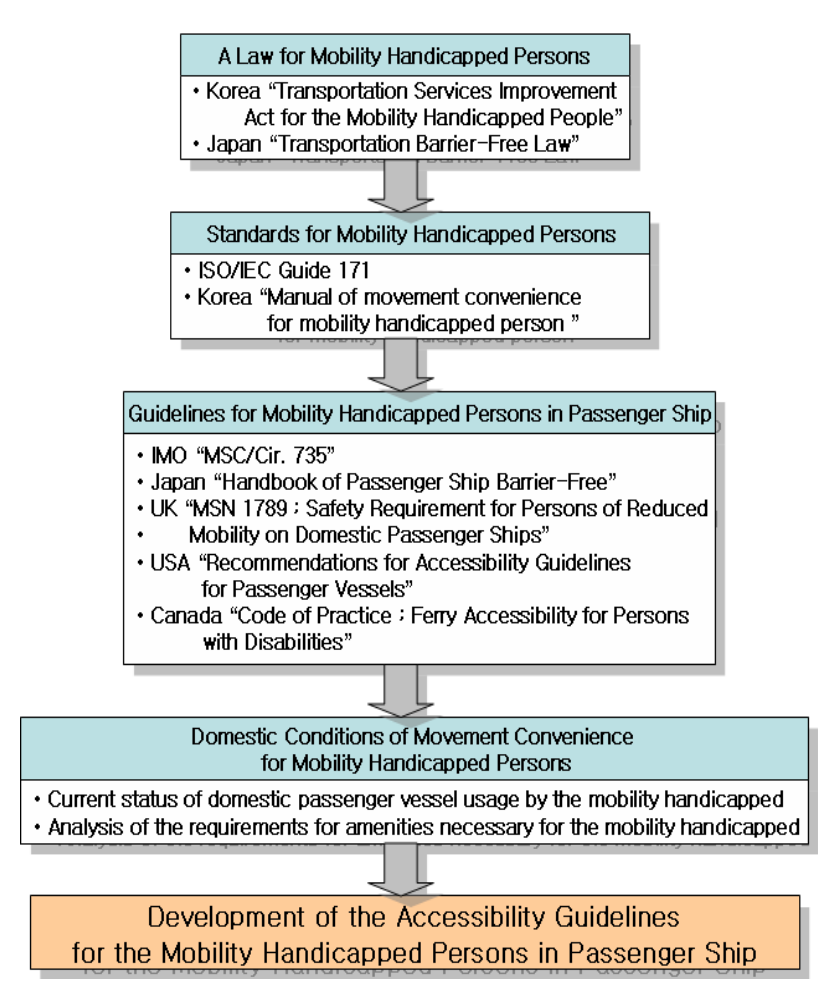

Fig. 1 Process Chart for the Development of the Accessibility Guidelines for Mobility Handicapped Persons

\footnotetext{
† Corresponding author, hongtae.kim@kiost.ac 042)866-3643

* jklee@kiost.ac, 042)866-3350

Note) This paper is revoised and expanded version of the paper "The Analysis of the Accessibility Improvement Plan for the Mobility Handicapped Persons in Passenger Ship" presented at the July 2008 International Conference on Interfaces and Human Computer Interaction
} 


\section{Review of domestic and foreign criteria}

In domestic, any using criteria for mobility handicapped persons in the vessel have not been developed. The only study on usage for mobility handicapped persons in the vessel was "An improvement Plan of Usability and Convenience for the Mobility Handicapped Person in Passenger Ship" conducted by Korea Ocean Research and Development Institute (KORDI) in 2004(Kim, 2004).

For terrestrial traffic, a number of researches having been conducted for mobility handicapped persons. The Korea Transport Institute (KOTI) performed basic study to improve the welfare transportation services for the mobility handicapped persons through a lot of relational studies. Some province governments perform similar studies, too(Sul, 2004)(Shin, 2002).

In foreign, Japan and the West have been making relational techniques, guidelines and regulations. A representative example is "The task of converting a ship as barrier free"(Fig. 2). In Japan, "Traffic Ecology Mobility Foundation" takes whole charge of the conversion of a traffic system as barrier free. The concern of barrier free traffic in Japan started 20 years ago. However, it began around the railroad traffic field, ten years ago. And barrier free traffic system is required by law; the rule for improvement of movement of elder and handicapped persons by public traffic vehicles (ECOMO, 2000).

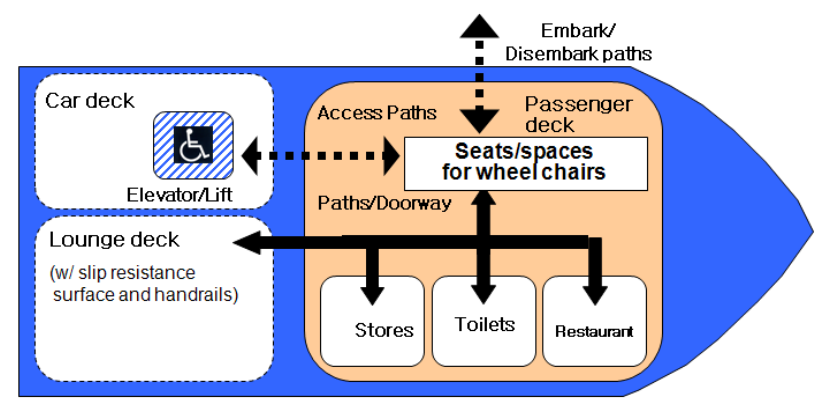

Fig. 2 The Concept of Barrier-free Ship

In West, UK, America, Austria and Canada developed and spread the relational guidelines. The guideline, "Guidance on the design of large passenger ships and passenger infrastructure-meeting the needs of disabled people" of maritime traffic in UK, was created by DPTAC (The Disabled Persons Transport Advisory Committee) and announced officially in April 2000 as the manual of the government without a legal binding force(DPTAC, 2000).
America established "The Americans with Disabilities Act; ADA" which prohibits comprehensively and obviously discrimination against handicapped persons. And they are propelling all clearance of the physical and social discrimination against the handicapped persons(ATC, 2000)(PVAAC, 2000). In America, they are dealing with the problem of handicapped persons as problem of human rights and are obligating the traffic service to be based on the human right.

In Austria, the Human Right and Opportunity Equality Committee prescribes relational guidelines based on prohibition law about discrimination against handicapped persons. In June 1996, “Australian Transport Council” published a guideline; "Disability standards for accessible public transport."

The IMO's Maritime Safety Committees (MSCs) approved "Recommendation on the design and operation of passenger ships to respond for elderly and disabled person's needs", prepared by Design \& Equipment Sub-committee (DE) in International Maritime Organization (IMO), in June 1996 (IMO, 1996).

\section{Mobility facility condition in domestic passenger ship for mobility handicapped person}

The purpose of the actual research on mobility facility in domestic coastal passenger ship is to survey facilities for mobility handicapped persons in domestic coastal passenger ship. Through the research, we try to find reference data to develop the barrier free ship and to renovate facilities in the ship.

Over 154 ships of 60 marine transportation companies were questioned. The questionnaire was divided into two categories. One is to write enterprise's opinion about mobility in passenger ship, and the other is to write current situation of mobility facilities in each passenger ship.

Through the survey, it was found that the companies which recognize the necessity of mobility facilities for mobility handicapped persons were 46 and it took 87 percents of the whole. Based on the statistics, it can be concluded that public relations of government and relational organs were effective to make companies recognize the necessity of mobility facilities for mobility handicapped persons.

Furthermore, those were revealed that 13 percents of companies answered "I don't know", 11 percents answered "Opposition" and 76 percents answered "actively participation" or "agreement" about "the task of converting 
a ship to barrier free" of government. The answer for the question that "How large do you think the support rate of government for mobility facilities in passenger ship should be?" was averagely over 80 percents of whole amount.

It was revealed that dissolution of barriers in the handicapped person's rest room and the passage was urgent in Fig. 3 shows the facilities that need to be improved.

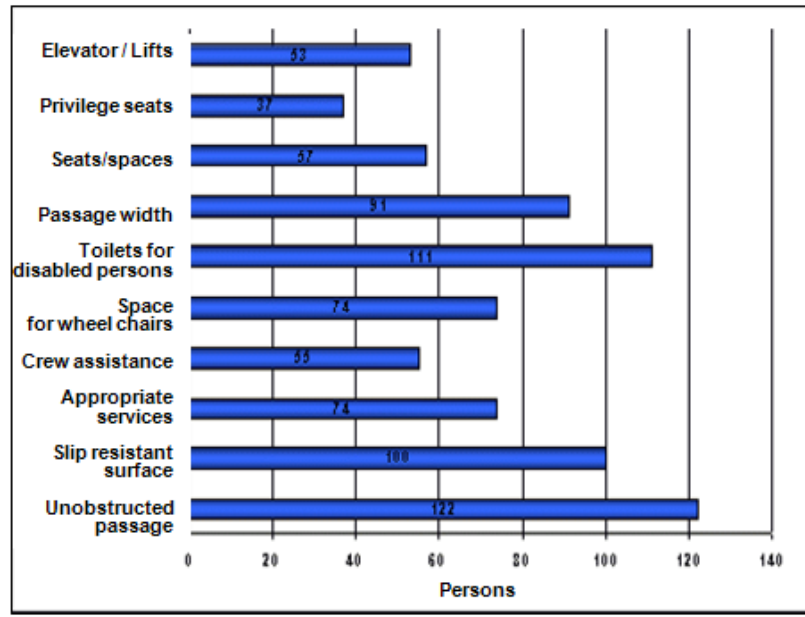

Fig. 3 Facilities Needed to be Improved

As for the boarding facilities for embarking on passenger ships, a stepped embarking device is most popular device which are generally used in various ships. The flat is generally used in the most of the ships except car-ferry. However, an embark bridge is used only in three ships. Car-ferries are found to use the lamp gate.

Width of access for boarding is shown in Fig. 4. As can be found in the figure, most of the entrance width is found to be $1000 \sim 2000 \mathrm{~mm}$. Besides, It can be found that car-ferries have the most portions in that case. Less than 20 percents of the ship has below $800 \mathrm{~mm}$ of width, and wheelchair could not pass through such width. Also, coaming height on deck passages is shown in Fig. 5.

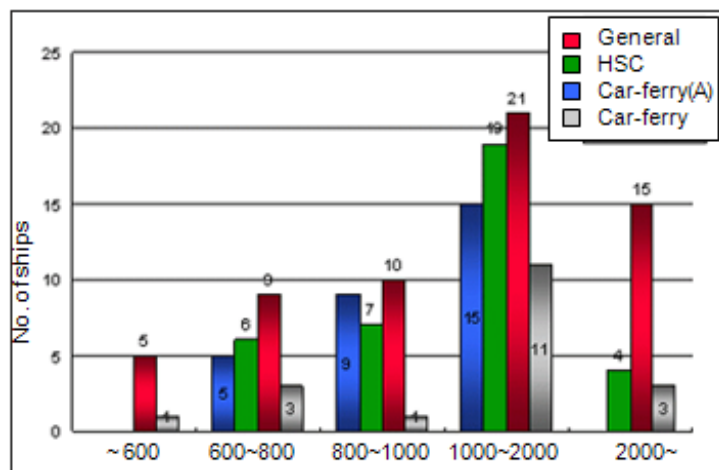

Fig. 4 Width of Access for Boarding

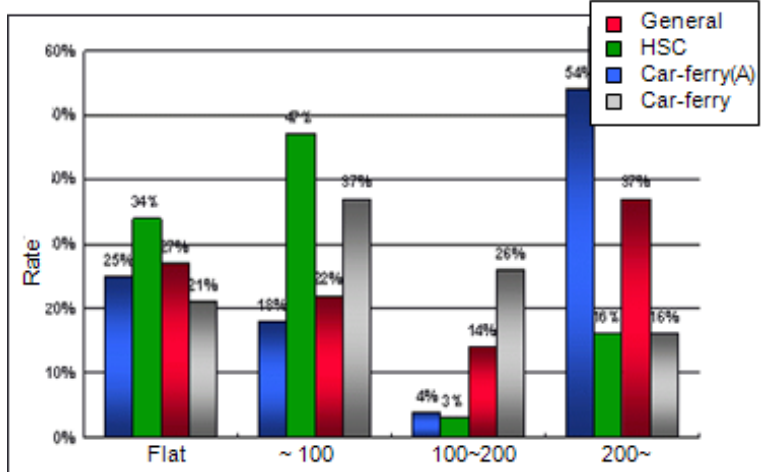

Fig. 5 Coaming Height on Deck Passages

\section{Accessibility Guidelines for the Mobility Handicapped Persons in Passenger Ship}

In "Transportation Services Improvement Act for the Mobility Handicapped People", the type of mobility facilities were classified by the kinds of transportation. This rule has started since January 27, 2006. Like other means of transportation, 9 mobility facilities were mentioned for a ship. There are many difficult problems to apply this rules and regulations to the maritime transportation companies and the shipbuilding companies because contents of those rules and regulations are so ambiguous.

In the study, "Accessibility Guidelines for the Mobility Handicapped Persons in Passenger Ship" was developed to solve this problem. The purpose of this criterion helps to apply "Transportation Services Improvement Act for the Mobility Handicapped People”.

Basically, criterion of facility and structure was set up to consider that elder and handicapped persons could embark/disembark, move in the ship, and use convenience facilities without inconvenience, by himself/herself.

To develop the accessibility guidelines, domestic and foreign relational statute, criteria and guideline for maritime traffic were investigated.

The guideline is composed of an outline, a method of usage, content of criteria, appendix and so on. The developed guideline will be spread to the maritime transportation companies and the shipbuilding companies just after verification of relational experts in 2007.

Table 1 shows detail contents of the accessibility guidelines. The accessibility guidelines are composed of 3 items of information support, mobility support and onboard equipment and 13 sub-items. 
Table 1 Contents of the Accessibility Guidelines for Mobility Handicapped Persons

\begin{tabular}{|c|l|}
\hline \multirow{4}{*}{ Items } & \multicolumn{1}{|c|}{ Sub-items } \\
\hline \multirow{4}{*}{$\begin{array}{c}\text { Information } \\
\text { Support }\end{array}$} & Onboard Announcement \\
\cline { 2 - 2 } & Electronic Signage \\
\cline { 2 - 2 } & Display of Departure-ArrivalPort \\
\cline { 2 - 2 } & Accessible Signage \\
\cline { 2 - 2 } Mobility & Tactile Surface \\
\hline \multirow{4}{*}{ Support } & Elevator / Lifts \\
\cline { 2 - 2 } & Doors \\
\cline { 2 - 2 } & Stairs \\
\cline { 2 - 2 } & Deck Passages \\
\hline \multirow{4}{*}{$\begin{array}{l}\text { Onboard } \\
\text { Equipment }\end{array}$} & $\begin{array}{l}\text { Space for wheel chairs \& Privilege } \\
\text { seats }\end{array}$ \\
\cline { 2 - 2 } & Toilets for disabled persons \\
\cline { 2 - 2 } & Deck \\
\cline { 2 - 2 } & Restaurant \\
\hline
\end{tabular}

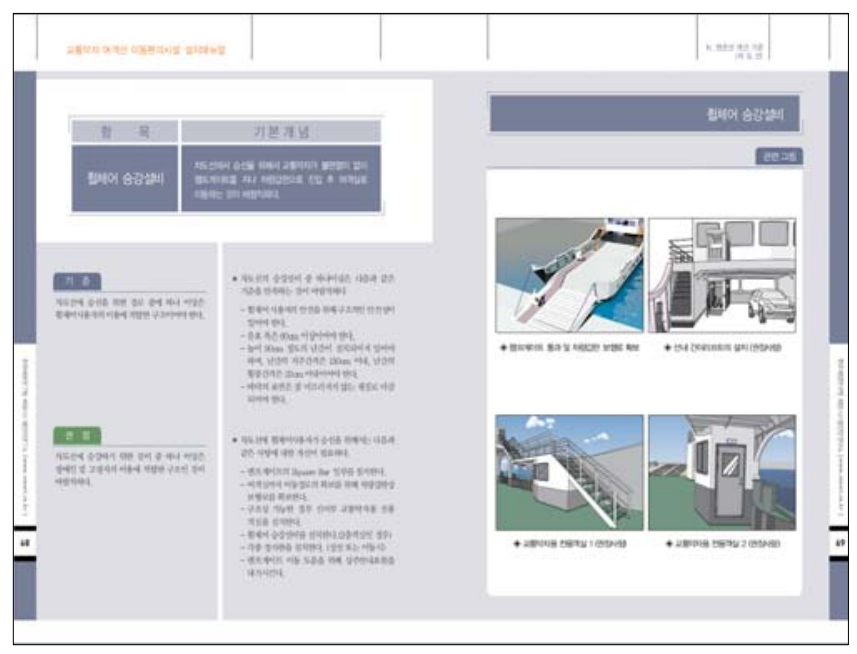

Fig. 6 Example of the Accessibility Guidelines for Mobility Handicapped Persons (Car Ferry)

Also, the accessibility guidelines state item name, basic concept, criteria, recommendation, explanation and illustration for each sub-item. Fig. 6 shows the criteria of mobility facility for car-ferry.

\section{Results}

Generally a passenger ship requires the improvement of more detailed and strengthened convenience for mobility handicapped person than other transportation systems of train, airplane, subway and bus, because passengers should accommodate and tour inside the ship, in case of long voyage. In other words, Mobility handicapped person should be supported to move, embarking/disembarking a ship more safely and conveniently.

This research was studied since 2005, and the draft have been developed as "Accessibility Guidelines for the Mobility Handicapped Persons in Passenger Ship", which could be referred when new ship is to be built or existing ship is to be renovated. For the development, relational statute in domestic and foreign, criteria and guideline for maritime traffic were investigated and evaluated. Furthermore, a facility improvement countermeasure about an existing passenger ship was presented.

The supplemented of the accessibility guidelines will be completed including a facility improvement countermeasure about an existing passenger ship. This guideline will be spread over the relational maritime transportation companies and shipbuilding companies. Furthermore, development and supply to majority mobility facility are planned.

We expect that passenger ship which is outstripped most was changed more safe and pleasant through the accessibility guidelines. Also, we respect the revitalization and development of shipbuilding material industries which are relatively outstripped compared with shipbuilding industries, because we reserve development ability of mobility facility for mobility handicapped person in passenger ship. Through the various facility development and supply to transportation services improvement for mobility handicapped person in passenger ship, the demand on the elegance of coast transportation will be increased. Furthermore, increased demand will bring about national concern on the sea culture and sea sight-seeing as well as revitalization of domestic leisure industry.

\section{Acknowledgements}

This study was financially supported by the Ministry of Land, Transport and Maritime Affairs of Korea. (Development of barrier-free ship for mobility handicapped persons)

\section{References}

[1] ATC(2000), "Americans with Disabilities Act Accessibility Guidelines for Buildings \& Facilities", U.S. Architectural \& Transportation Barriers Compliance Board.

[2] DPTAC(2000), "The Design of Large Passenger Ships 
\& Passenger Infrastructure", U.K. Disabled Persons Transport Advisory Committee.

[3] ECOMO(2000), "Barrier-Free Design Manual for Passenger Ship", Japanese Transportation ECOMO Foundation.

[4] IMO(1996), MSC/Circ. 735, "Recommendation on the Design and Operation of Passenger Ships to Respond to Elderly and Disabled Persons' Needs".

[5] Kim, H.(2004), "An Improvement Plan of Usability and Convenience for the Mobility Handicapped Person in Passenger Ship", UCE0089F-04090, Maritime \& Ocean Engineering Research Institute/KORDI.

[6] MCT(2006), "Transportation Services Improvement Act for the Mobility Handicapped People", Ministry of Construction \& Transportation, Korea.

[7] PVAAC(2000), "Recommendations for Accessibility Guidelines for Passenger Vessels", U.S. Architectural and Transportation Barriers Passenger Vessel Access Advisory Committee.

[8] Shin, Y.(2002), "An Evaluation and Improvement Plan of Walking Environment for the Mobility Handicapped", Korea Transport Institute.

[9] Sul, J.(2004), "Improvement Measures in the Welfare Transportation Services for the Mobility Handicapped and Elderly People", Korea Transport Institute.

Received 18 October 2012

Revised 29 November 2012

Accepted 29 November 2012 